\title{
The costs of delivering human papillomavirus vaccination to Grade 4 learners in KwaZulu-Natal, South Africa
}

\author{
I Moodley, ${ }^{1} \mathrm{PhD}$; N Tathiah, ${ }^{2}$ BSc Hons, MB ChB, Dip HIV Man (SA), MS (Epi), FCPHM, MMed; B Sartorius, ${ }^{3}$ PhD \\ ${ }^{1}$ Health Outcomes Research Unit, Discipline of Public Health Medicine, College of Health Sciences, Nelson R Mandela School of Medicine, \\ University of KwaZulu-Natal, Durban, South Africa \\ ${ }^{2}$ School of Nursing and Public Health, College of Health Sciences, Nelson R Mandela School of Medicine, University of KwaZulu-Natal, \\ Durban, South Africa \\ ${ }^{3}$ Discipline of Public Health Medicine, School of Nursing and Public Health, College of Health Sciences, University of KwaZulu-Natal, \\ Durban, South Africa
}

Corresponding author: I Moodley (moodleyi15@ukzn.ac.za)

Background. The national human papillomavirus (HPV) vaccination roll-out in South Africa provides two doses of Cervarix to all female Grade 4 learners in state schools. This study estimated the costs of vaccinating all learners in KwaZulu-Natal Province (females or males and females) using either the two- or three-dose strategies for both the bivalent and quadrivalent vaccines.

Objective. To determine costs of the HPV vaccination programme in KwaZulu-Natal.

Methods. Costs were determined adapting World Health Organization vaccination costing guidelines.

Results. The 2014 current cost of delivering three doses of Gardasil was ZAR510 per learner. The projected cost of delivering Cervarix to female learners at two or three doses over the period 2014 - 2018, adjusted for inflation, was ZAR172 717342 and ZAR250 048 426, respectively. Similarly, the cost for Gardasil at these doses was ZAR197 482200 and ZAR287 194 361, respectively. For male and female learners the cost for Cervarix over this period at two or three doses was ZAR337 101132 and ZAR540 150 713, respectively. Similarly, the cost for Gardasil at these doses was ZAR426 597971 and ZAR620 392 784, respectively. Accounting for population variation for females over 5 years, the cost of two doses of Cervarix ranged from ZAR168 888677 to ZAR 176545977 at the lower and upper 95\% confidence intervals (CIs), respectively. For three doses the cost ranged from ZAR244 505544 to ZAR255 591263 at the lower and upper 95\% CIs, respectively. Similarly, the cost for two doses of Gardasil ranged from ZAR193 104566 to ZAR201 859 798. For three doses the cost ranged from ZAR280 828057 to ZAR293 560614. Conclusion. This study gives decision makers a basis for structured planning and cost apportionment to ensure effective roll-out of the HPV vaccination programme.

S Afr Med J 2016;106(5):497-501. DOI:10.7196/SAMJ.2016.v106i5.9988

Cervical cancer is the second most common cancer after breast cancer in South African (SA) women. ${ }^{[1]}$ Persistent human papillomavirus (HPV) infection is linked to both cervical cancer and genital warts. ${ }^{[2]}$ High-risk genotypes HPV 16 and 18 are associated with $70 \%$ of cervical cancers, and HPV 6 and 11 with $90 \%$ of genital warts. ${ }^{[2]}$

Vaccination against HPV infection offers protection against the development of cervical cancer, especially if administered before the onset of sexual activity. ${ }^{[2]}$ Two vaccines are available in SA: Cervarix (bivalent vaccine with activity against HPV 16 and 18) and Gardasil (quadrivalent vaccine against HPV 6,11, 16 and 18). ${ }^{[2]}$

High-income countries such as the USA have introduced HPV vaccination for both males and females. ${ }^{[3]}$ However, the World Health Organization (WHO) recommends that in resource-constrained settings it is more cost-effective to vaccinate only females. ${ }^{[2]}$

Demonstration of the non-inferiority of the two-dose v. the threedose regimen ${ }^{[3,4]}$ probably provided the basis for the SA government to nationally roll out HPV vaccination (two doses of Cervarix given 6 months apart) to all female Grade 4 learners at government schools, targeting approximately 500000 learners. ${ }^{[5]}$

According to the United Nations Population Fund, a key consideration in the integration of HPV vaccine delivery into health systems is budgeting for vaccines and service delivery costs. ${ }^{[6]}$

\section{Objective}

Modelling for this costing study was based on the HPV vaccination demonstration project. $^{[7]}$ The objective was to use the costs determined for the demonstration project as the basis for estimating the costs of vaccinating all Grade 4 (9 - 10-year-old) learners in KwaZulu-Natal Province (KZN) (female compared with both male and female learners) using either the two- or three-dose regimens for both Cervarix and Gardasil.

\section{Methods}

This was a retrospective cost analysis using data collected during the HPV vaccination demonstration project conducted in $\mathrm{KZN}$ in $2011 .^{[7]}$

\section{Data collection and analysis}

Costs of the HPV vaccination demonstration project ${ }^{[7]}$

Financial and economic costs were estimated using adapted versions of established costing guidelines. ${ }^{[8]}$ Actual expenditures (2014 costs) were determined for personnel, goods and services. Economic costs included donated vaccines.

Cost data were distributed into four categories: personnel costs based on government salary scales for 2014; recurrent costs for procurement of vaccines and waste management; transport costs (based on the Automobile Association of South Africa rates); and capital costs for cold boxes and additional refrigerators. Capital costs for equipment already available at the hospital pharmacy were not included.

Costs of training and community mobilisation and information, education and communication were included for the demonstration project and then treated as start-up costs and annualised over 5 years. Building costs and overheads (e.g. maintenance, water and electricity) were not included. 
Costs assumed a price per dose of USD8 and USD10 for the bivalent and quadrivalent vaccines, respectively. ${ }^{[9]}$

All cost data were adjusted to the year 2014 using country-specific gross domestic product (GDP) inflators ${ }^{[10]}$ and were converted to US dollars using average 2014 exchange rates of $11 \mathrm{ZAR}=1 \mathrm{USD}$. Using an ingredients approach, the financial and economic costs were determined per fully immunised female learner.

\section{Estimated costs of vaccinating all female learners (Grade 4, age 9 and 10 years) in KZN}

The model estimated the costs of a schoolbased delivery programme targeting female learners in Grade 4 (age 9 and 10 years). The model was constructed to estimate the incremental economic costs of a scaled-up vaccination programme in $\mathrm{KZN}$, reflecting the plans of the SA government. ${ }^{[5]}$
The model involved two steps: quantities of resources were estimated on the processes used during the school-based vaccination project, ${ }^{[7]}$ for input into the WHO planning and costing tool for estimating the costs of introducing HPV vaccines. ${ }^{[8]}$ Unit costs or prices were assigned to the necessary inputs. The model calculated total costs for KZN and the cost per fully immunised learner.

Costs were estimated for a 'base-case scenario' using a number of 'base-case' assumptions (Table 1). Low-cost assumptions assumed only two vaccinations, and excluded HPV vaccine costs. High-cost assumptions assumed three doses of the vaccine and included vaccine costs.

Sensitivity analyses were carried out using estimates of the consumer price index (CPI) and population variations to generate the largest possible range of costs in an analysis of extremes. Fig. 1 shows the observed and projected population of female and

Table 1. Input parameters for modelling of a scaled-up vaccination programme for KZN

\begin{tabular}{llll}
\hline & Base case & Low cost & High cost \\
\hline Vaccinations, $n$ & 3 & 2 & 3 \\
Additional vaccination trips, $n$ & 3 & 2 & 4 \\
Total km for school visited & 1550 & 1550 & 1550 \\
Eligible schools, $\%$ & 80 & 75 & 100 \\
Wastage rate (vaccines), \% & 1 & 0.5 & 2 \\
Vaccination coverage, $\%$ & & & \\
Rate for first dose & 99.69 & & \\
Rate for second dose & 97.92 & & \\
Rate for third dose & 97.82 & & \\
Vaccine prices, USD & 0 & &
\end{tabular}

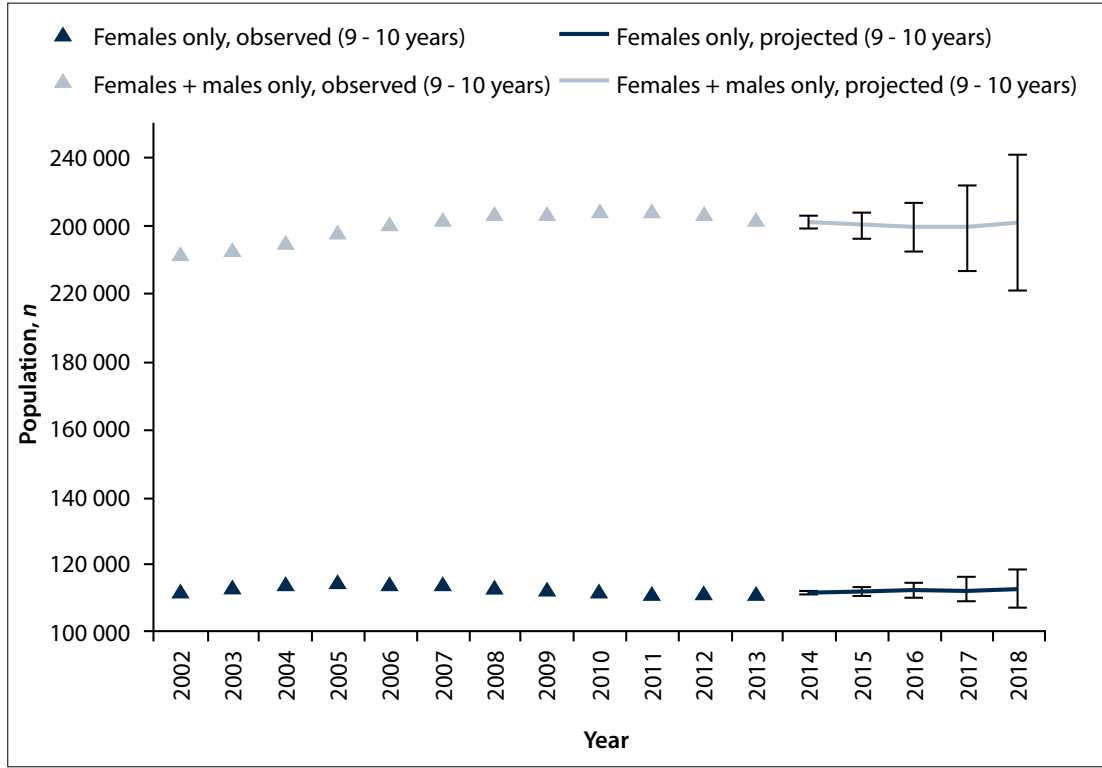

Fig. 1. Observed and projected populations of female and male learners in KZN eligible for HPV vaccination. male learners in $\mathrm{KZN}^{[11]}$ eligible for $\mathrm{HPV}$ vaccination. Using data for 2002 - 2013, various non-linear regression curves were fitted to the data and assessed as to which fitted the data best for the observed period. This best-fit non-linear curve and associated 95\% confidence intervals (CIs) (uncertainty) were used to project population totals by gender and year for the period 2014 - 2018. This projection was then multiplied by the projected costs and also took into account inflation to estimate variations in costs of HPV vaccine provision. The estimated average CPI increase was obtained from Statistics South Africa to calculate the nominal increase in prices for the period $2014-2018 .^{[12]}$

All analyses were conducted using Stata 13.0 SE (Stata Statistical Software: Release 13, StataCorp LP, USA). Non-linear regression analyses were conducted using the 'nl' programme in Stata. ${ }^{[13]}$

\section{Ethical considerations}

Ethical approval for the demonstration project was obtained from the Institutional Ethics Committee at the University of Cape Town (HREC REF:012/2011). Approval to conduct the project in the two districts was obtained from the KZN provincial departments of health and education.

\section{Results}

\section{Total cost of the HPV demonstration} project

The economic cost per learner (Table 2) of delivering three doses of Gardasil HPV vaccine was ZAR510.28(USD46.39). Administration, supervision, social mobilisation and training accounted for $35.3 \%$ of total project costs. Procurement accounted for $64.7 \%$ or ZAR211 860 (USD19 260) of total costs. Based on the cost per learner, the total economic project costs of delivering three doses of HPV vaccine to 963 female learners in the Zululand District were estimated to be ZAR491 400 (USD44 673).

Table 2. Total economic costs for the HPV demonstration project (three doses)

\begin{tabular}{ll}
\hline & Cost, ZAR \\
\hline School health teams & 118.25 \\
Pharmacy & 8.17 \\
Consumables & 5.26 \\
Fridge & 8.31 \\
Printing & 2.92 \\
Transport & 37.37 \\
Gardasil & 330.00 \\
Cost/learner & 510.28
\end{tabular}




\section{Costs of a KZN provincial vaccination programme} Projected costs over a 5-year period of providing HPV vaccines to female learners only or to both male and female learners

The costs of providing a two- or three-dose vaccine (Cervarix or Gardasil) to all eligible learners in KZN were determined.

Table 3 shows the estimated incremental economic costs of a scaledup vaccination programme delivering two and three doses of HPV vaccine (Cervarix or Gardasil) to female learners alone. The costs of delivering two and three doses to both female and male learners are set out in Table 4 (Cervarix) and Table 5 (Gardasil). The costs of procurement, including vaccines and supplies, shipment of vaccines to regional level, transport to districts and distribution to health facilities, account for the largest share of financial and economic costs (35.3\% and $64.7 \%$, respectively). The costs of vaccination include the cost of nurses' and teachers' time and administration.

Over the period 2014 - 2018, the projected cost of providing Cervarix at two doses to female learners only, adjusted for inflation (Table 3),

Table 3. Projected baseline costs (ZAR) over a 5-year period for providing HPV vaccines (Cervarix or Gardasil at either two or three doses) to female learners only

\begin{tabular}{llllll}
\hline & \multicolumn{2}{c}{ Cervarix } & & \multicolumn{2}{c}{ Gardasil } \\
\cline { 2 - 3 } \cline { 6 - 7 } Year & 2 doses & 3 doses & & 2 doses & 3 doses \\
\hline 2014 & 34397341 & 49798132 & & 39329361 & 57195892 \\
2015 & 34470405 & 49903909 & & 39412900 & 57317382 \\
2016 & 34543468 & 50009685 & & 39496440 & 57438872 \\
2017 & 34616532 & 50115462 & & 39579980 & 57560362 \\
2018 & 34689596 & 50221238 & & 39663519 & 57681852 \\
Total & 172717342 & 250048426 & & 197482200 & 287194361
\end{tabular}

ranged from ZAR34 397341 (USD3 127 031) to ZAR34 689596 (USD3 153 600), with a total overall cost of ZAR172 717342 (USD15 701577 ) over the 5 -year period. For Cervarix at three doses, the cost ranged from ZAR49 798132 (USD4 527 103) to ZAR50 221238 (USD4 565 567), with a total overall cost for the 5-year period of ZAR250 048426 (USD22 731 675). The percentage incremental cost of providing a three-dose regimen was in the order of $44.8 \%$ over the 5 -year period.

Similarly, the projected cost for providing Gardasil at two doses to female learners only over the same period, adjusted for inflation (Table 3), ranged from ZAR39 329361 (USD3 575 396) to ZAR39 663519 (USD3 605 774), with a total overall cost of ZAR197 482200 (USD17 952 927). For Gardasil at three doses, the cost ranged from ZAR57 195892 (USD5 199 627) to ZAR57 681852 (USD5 243 805), with a total overall cost for the 5-year period of ZAR287 194361 (USD26 108 578). The percentage incremental cost of providing a three-dose regimen was in the order of $45.7 \%$ over the 5 -year period. The incremental cost of providing the two- or threedose regimen of Gardasil over the 5-year period was ZAR24 764857 (USD2 251 351) and ZAR37 145935 (USD3 376 903), respectively.

The projected cost of providing Cervarix at two doses to both male and female learners for the period 2014 - 2018 (Table 4) ranged from ZAR67 858042 (USD6 168 913) to ZAR82 345798 (USD7 485 982), and for Cervarix at three doses from ZAR98 240260 (USD8 930 933) to ZAR119 214648 (USD10 837 695). The total overall cost for the 5-year period for Cervarix at two or three doses was ZAR373 101312 (USD30 696 679) and ZAR540 150713 (USD4 9137 012), respectively.

Similarly, for Gardasil at two doses to male and female learners (Table 5), the projected cost over the 5-year period ranged from ZAR77 587782 (USD10 837 695) to ZAR94 152846 (USD8 559 350), and for Gardasil at three doses from ZAR112 834338 (USD10 257 667) to ZAR136 924576 (USD12 447 689). The total

Table 4. Projected baseline costs (ZAR) over a 5-year period for providing HPV vaccine (Cervarix at either two or three doses) to female and male learners

\begin{tabular}{llllllll}
\hline & \multicolumn{3}{c}{ 2 doses } & & \multicolumn{3}{c}{ 3 doses } \\
\cline { 2 - 4 } \cline { 6 - 8 } Year & Mean & Lower 95\% CI & Upper 95\% CI & & Mean & Lower 95\% CI & Upper 95\% CI \\
\hline 2014 & 67858042 & 67338034 & 68378081 & & 98240260 & 97487427 & 98993137 \\
2015 & 70854600 & 69625058 & 72084141 & & 102578472 & 100798426 & 104358518 \\
2016 & 74144035 & 71681793 & 76606278 & & 107340693 & 103776026 & 110905361 \\
2017 & 77898837 & 73467423 & 82330251 & & 112776640 & 106361140 & 119192140 \\
2018 & 82345798 & 74938302 & 89753257 & & 119214648 & 108490579 & 129938663 \\
Total & 373101312 & 357050610 & 389152007 & 540150713 & 516913598 & 563387819
\end{tabular}

Table 5. Projected baseline costs (ZAR) over a 5-year period for providing HPV vaccine (Gardasil at either two or three doses) to female and male learners

\begin{tabular}{|c|c|c|c|c|c|c|}
\hline \multirow[b]{2}{*}{ Year } & \multicolumn{3}{|c|}{2 doses } & \multicolumn{3}{|c|}{3 doses } \\
\hline & Mean & Lower 95\% CI & Upper $95 \%$ CI & Mean & Lower 95\% CI & Upper 95\% CI \\
\hline 2014 & 77587782 & 76993213 & 78182385 & 112834338 & 111969669 & 113699059 \\
\hline 2015 & 81013997 & 79608159 & 82419834 & 117817013 & 115772533 & 119861494 \\
\hline 2016 & 84775084 & 81959796 & 87590372 & 123286686 & 119192470 & 127380903 \\
\hline 2017 & 89068263 & 84001456 & 94135070 & 129530170 & 122161615 & 136898725 \\
\hline 2018 & 94152846 & 85683236 & 102622414 & 136924576 & 124607394 & 149241696 \\
\hline Total & 426597971 & 408245859 & 444950075 & 620392784 & 593703680 & 647081877 \\
\hline
\end{tabular}


Table 6. Baseline and 95\% CI HPV vaccine (Cervarix and Gardasil) administration costs (ZAR) for female learners

\begin{tabular}{|c|c|c|c|c|}
\hline \multirow[b]{2}{*}{ Year } & \multicolumn{2}{|c|}{ Cervarix: Female learners } & \multicolumn{2}{|c|}{ Gardasil: Female learners } \\
\hline & 2 doses, mean $(95 \% \mathrm{CI})$ & 3 doses, mean $(95 \% \mathrm{CI})$ & 2 doses, mean $(95 \% \mathrm{CI})$ & 3 doses, mean $(95 \% \mathrm{CI})$ \\
\hline 2014 & $\begin{array}{l}34397341 \\
(34253568 \text { - } 34541084)\end{array}$ & $\begin{array}{l}49798132 \\
(49589987-50006233)\end{array}$ & $\begin{array}{l}39329361 \\
(39164973-39493714)\end{array}$ & $\begin{array}{l}57195892 \\
(56956826-57434907)\end{array}$ \\
\hline 2015 & $\begin{array}{l}34470405 \\
(34146647 \text { - } 34794163)\end{array}$ & $\begin{array}{l}49903909 \\
(49435193-50372624)\end{array}$ & $\begin{array}{l}39412900 \\
(39042720-39783080)\end{array}$ & $\begin{array}{l}57317382 \\
(56779037-57855728)\end{array}$ \\
\hline 2016 & $\begin{array}{l}34543468 \\
(33925965 \text { - } 35160972)\end{array}$ & $\begin{array}{l}50009685 \\
(49115705-50903665)\end{array}$ & $\begin{array}{l}39496440 \\
(38790396 \text { - } 40202484)\end{array}$ & $\begin{array}{l}57438872 \\
(56412087-58465658)\end{array}$ \\
\hline 2017 & $\begin{array}{l}34616532 \\
(33558072-35674992)\end{array}$ & $\begin{array}{l}50115462 \\
(48583095-51647828)\end{array}$ & $\begin{array}{l}39579980 \\
(38369753 \text { - } 40790205)\end{array}$ & $\begin{array}{l}57560362 \\
(55800355 \text { - } 59320369)\end{array}$ \\
\hline 2018 & $\begin{array}{l}34689596 \\
(33004425-36374766)\end{array}$ & $\begin{array}{l}50221238 \\
(47781563-52660913)\end{array}$ & $\begin{array}{l}39663519 \\
(37736723-41590315)\end{array}$ & $\begin{array}{l}57681852 \\
(54879752-60483953)\end{array}$ \\
\hline Total & $\begin{array}{l}172717342 \\
(168888677-176545977)\end{array}$ & $\begin{array}{l}250048426 \\
(244505544-255591261)\end{array}$ & $\begin{array}{l}197482200 \\
(193104566-201859798)\end{array}$ & $\begin{array}{l}287194361 \\
(280828057-293560614)\end{array}$ \\
\hline
\end{tabular}

overall cost for the 5-year period for Gardasil at two or three doses was ZAR426 597971 (USD38 781634 and ZAR620 392784 (USD56 399 344), respectively.

The incremental cost of extending the vaccination to male learners for the two- and three-dose regimens of Cervarix was ZAR200 383970 (USD18 217 082) and ZAR290 102288 (USD26 372 935), respectively, and that for the two- and threedose regimens of Gardasil ZAR229 115771 (USD20 829 115) and ZAR333 198423 (USD30 290 766), respectively.

Projected annual costs over a 5-year period for fully immunised female learners, taking into account population variation estimates

Sensitivity analysis used the baseline costs for 2014 and 95\% CIs that take into account variations in the population estimates as shown in Fig. 1. The assumption is that full coverage based on economic costs, i.e. funding for the vaccines, will be provided by KZN Department of Health. The distribution of costs across programme elements was based on the HPV vaccination demonstration project shown in Table 2.

The projected costs based on the baseline cost of providing HPV vaccines to female learners (Table 3 ) adjusted for population variations (with 95\% CIs) were determined for both Cervarix and Gardasil (two- and three-dose regimens) for each of the years from 2014 to 2015 (Table 6). The overall projected cost of delivering Cervarix at two and three doses to female learners for the period 2014 - 2018 was ZAR172 717342 (USD15 701 577) and ZAR250 048426 (USD22 731) respectively (Table 6). Taking into account population variation over the same period, the cost of a two-dose regimen ranged from ZAR168 888677 (USD15 353 516) to ZAR176 545977 (USD16 049 634) at the lower and upper 95\% CIs, respectively. In contrast, for the three-dose regimen the cost ranged from ZAR244 505544 (USD22 227 777) to ZAR255 591263 (USD23 235 569) at the lower and upper 95\% CIs, respectively.

Similarly, the overall projected cost of delivering Gardasil at two and three doses to female learners was ZAR197 482200 (USD17 952 927) and ZAR287 194361 (USD26 108 578), respectively (Table 6). Taking into account population variation over the 5 -year period, the cost of a two-dose regimen ranged from ZAR193 104566 (USD17 554 961) to ZAR201 859798 (USD18 350 891) at the lower and upper 95\% CIs, respectively. In contrast, for the three-dose regimen the cost ranged from ZAR280 828057 (USD25 529 823) to
ZAR293 560614 (USD26 687 329) at the lower and upper 95\% CIs, respectively.

Regardless of whether Cervarix or Gardasil is provided and irrespective of the dosage regimen, the population projections suggest a negative growth at the lower limit of the CI over the 5-year period, resulting in a decrease in costs. At the upper limit of the CI the projections show a small increase in population growth, resulting in a marginal increase in costs.

\section{Discussion}

This costing study based on the HPV vaccination demonstration project ${ }^{17]}$ provides the basis for estimating the costs of including both female and male learners in the provincial HPV vaccination programme. Limited to the province of KZN, it did not take into account variations between districts, for example in terms of resources (availability and distribution of school health teams, transport, logistics, and cold-chain management) and urban populations. However, it provides the cost input parameters to monitor the implementation of the vaccination programme

While it is noted that the implementation of new health interventions in low- to middle-income countries may take time to achieve the anticipated public health outcomes, a cost-benefit analysis based on the number of cases of cervical cancers and HPVrelated warts averted should be undertaken to determine future downstream cost savings through the introduction of the HPV vaccination programme in SA.

A Tanzanian study that conducted a top-down analysis of the costs of delivering three doses of HPV vaccine to 4211 girls estimated the total economic costs to be USD349 000 (which included a vaccine price of USD5 per dose). ${ }^{[14]}$ This cost per fully immunised learner (USD78) is almost two-fold greater than reported in our study. However, when scaled up the Tanzanian costs are almost 50\% lower (USD46.5 v. USD26.4). Incremental economic scaled-up costs for schoolbased vaccination of 50290 girls were estimated at USD1.3 million. Economic scaled-up costs per fully immunised girl were USD26.41 per dose. Excluding vaccine costs, the vaccine could be administered at an incremental economic cost of USD3.09 per dose and USD9.76 per fully immunised girl. Financial scaled-up costs, excluding costs of the vaccine and salaries of existing staff, were estimated at USD1.73 per dose. ${ }^{[14]}$

A cross-country study conducted in Peru, Uganda and Vietnam estimated the economic delivery cost per vaccine as USD3.88 in 
Peru, USD3.15 (school based) and USD1.44 (integrated outreach) in Uganda, and USD2.08 (school based) and USD1.92 (integrated outreach) in Vietnam. ${ }^{[15]}$ The Tanzanian and other studies show that the lower economic costs per fully immunised learner are achieved not only through lower vaccine costs, but mainly through lower delivery costs. ${ }^{[14-15]}$

The cost-effectiveness of including boys in HPV vaccination programmes is dependent on vaccine pricing, HPV prevalence, and uptake of cancer screening and treatment. ${ }^{[16]}$

A cost utility study conducted in New Zealand ${ }^{[17]}$ found that it was not cost-effective to vaccinate boys in addition to girls. Significantly, for vaccination of boys to be cost-effective, the cost of the vaccine needs to be very low and administration costs minimal. ${ }^{[17]}$ Similarly, in Brazil it was found that it was not cost-effective to include boys. ${ }^{[18]}$

\section{Conclusion}

This study provides decision makers with a framework for allocating resources to determine financial and economic costs for structured planning to effectively roll out the HPV vaccination programme nationally. Costing studies can inform budget impact analyses and cost minimisation studies to decide on optimal delivery strategy.

A two-dose regimen of either Cervarix or Gardasil is less costly than three doses, with reported equivalent benefits. In low- to middle-income countries vaccination of female learners is more costeffective than vaccination of both males and females.

\section{References}

1. Bruni L, Barrionuevo-Rosas L, Albero G, et al. ICO Information Centre on HPV and Cancer (HPV Information Centre). Human Papillomavirus and Related Diseases in South Africa. Summary Report 2015-03-20. www.hpvcentre.net (accessed 2 April 2015)

2. World Health Organization. Human Papillomavirus Vaccines: WHO Position Paper. Wkly Epidemiol Rec 2. World Health Organization. Human Papillomavirus Vaccines: WHO Position Paper. Wkly Epidemiol Rec
2014;43(89):465-492. http://ac.els-cdn.com/S0264410X14016181/dx.doi.org/10.1016/j.vaccine.2014.12.002 (accessed 2 April 2015).
3. Centers for Disease Control and Prevention (CDC). Human papillomavirus vaccination coverage among adolescent girls, 2007-2012, and post licensure vaccine safety monitoring, 2006-2013. MMWR Morb Mort Wkly Rep 2013;62(29):591-595.

4. Dobson SR, McNeil S, Dionne M, et al. Immunogenicity of 2 doses of HPV vaccine in younger adolescents vs 3 doses in young women: A randomized clinical trial. JAMA 2013;309(17):1793-1802.
and DOI:10.1001/jama.2013.1625

5. National Department of Health, South Africa. Human Papilloma Virus (HPV) Vaccination Campaign. 2014. http://www.health.gov.za/ (accessed 26 March 2014)

6. United Nations Population Fund (UNFPA). Comprehensive cervical cancer prevention and control: Programme guidance for countries. Denmark. 2011. http://apps.who.int/iris/ bitstream/10665/144785/1/9789241548953_eng.pdf (accessed 26 March 2014).

7. Moodley I, Tathiah N, Mubaiwa V, Denny L. High uptake of Gardasil ${ }^{\circ}$ vaccine among 9 - 12-year-old schoolgirls participating in an HPV vaccination demonstration project in KwaZulu-Natal, South Africa. S Afr Med J 2013;103(5):318-321. DOI:10.7196/SAMJ.6414

8. World Health Organization. Guidelines for Estimating Costs of Introducing New Vaccines into the National Immunization System. Geneva: WHO, 2002. www.who.int/vaccines-documents/ (accessed 26 March 2014).

9. Union for International Cancer Control. UICC welcomes commitment to lower prices for HPV vaccines. http://www.uicc.org/programmes/uicc-welcomes-commitment-lowerprices- hpv-vaccines (accessed 30 June 2015)

10. Statistics South Africa. Exchange rate. http://zar.fxexchangerate. com/usd- 2014_02 28-exchange. Statistics South Africa. Exchange rate. http.
rates-history.html (accessed 30 June 2015).

11. Statistics South Africa. Census 2011: Provincial profile: KwaZulu-Natal. 2011. www.statssa.gov.za (accessed 26 March 2014)

12. Statistics South Africa. Consumer Price Index (CPI). http://www.statssa.gov.za (accessed 30 June 2015)

13. Danuso F. sg1: Nonlinear regression command. Stata Technical Bulletin 1991;1:17-19. Reprinted in Stata Technical Bulletin Reprints 1991;1:96-98

4. Quentin W, Terris-Prestholt F, Changalucha J. Costs of delivering human papillomavirus vaccination to schoolgirls in Mwanza Region, Tanzania. BMC Med 2012;10:137 DOI:10.1186/1741-7015-10-137

15. Levin C, van Minh H, Odaga J. Delivery cost of human papillomavirus vaccination of young adolescent girls in Peru, Uganda and Vietnam. Bull World Health Organ 2013;91:585-592. www. who.int/bulletin/volumes/91/8/12-113837/en (accessed 26 March 2014).

16. Kim JJ, Andres-Beck B, Goldie SJ. The value of including boys in an HPV vaccination programme: A colde of including boys in an HPV vaccination programm A cost effective
si.bjc. 6604023

17. Pearson AL, Kvizhinadze G, Wilson N, Smith M, Canfell K, Blakely T. Is expanding HPV vaccination pearson AL, Kvizhinadze G, Wilson N, Smith M, Canfell K, Blakely T. Is expanding HPV vaccination
programs to include school-aged boys likely to be value-for-money: A cost-utility analysis in country with an existing school-girl program. BMC Infect Dis 2014;14:351. DOI:10.1186/14712334-14-351

18. Goldie SJ, Kim JJ, Kobus K, et al. Cost-effectiveness of HPV 16, 18 vaccination in Brazil. Vaccine 2007;25(33):6257-6270. DOI:10.1016/j.vaccine.2007.05.058

Accepted 22 January 2016. 